\title{
Fruit-Promoting Smarter Lunchrooms Interventions: Results From a Cluster RCT
}

Katherine N. Greene, MPH, Gnel Gabrielyan, PhD, David R. Just, PhD, Brian Wansink, PhD

From the Charles H. Dyson School of Applied Economics and Management, Cornell University, Ithaca, New York

Address correspondence to: Brian Wansink, PhD, Cornell University, Charles H. Dyson School of Applied Economics and Management, 475 Warren Hall, Ithaca NY 14853. E-mail:

fblsubmission@cornell.edu. 
Introduction: The Smarter Lunchrooms Movement was developed to provide schools with simple, low-cost solutions to encourage students to make healthier food choices at school. The objective of this study was to evaluate the impact of fruit-promoting Smarter Lunchroom interventions on middle school students' selection and consumption of fruits.

Design: A 9-week cluster RCT was conducted using a pre-test/post-test control group design in upstate New York in February-April 2014.

Setting/participants: Ten middle schools (Grades 5-8) were recruited and randomized into a fruit intervention $(n=4)$, vegetable intervention $(n=3)$, or control group $(n=3)$. This article focuses only on the fruit intervention and control groups.

Intervention: The fruit intervention group made changes to the convenience, visibility, and attractiveness of fruit in their lunchrooms for a period of 6 weeks. The control group made no changes, and were offered Smarter Lunchrooms training post-intervention.

Main outcome measures: Selection and plate waste data were collected from February to April 2014, and analyzed in 2014-2015. Average selection, waste, and consumption of food items were computed, and the statistical differences between treatment and control groups were analyzed using $t$-test statistics and difference-in-difference analysis.

Results: Fruit selection increased overall by $36 \%(p<0.001)$, and fruit consumption increased overall by $23 \%(p<0.017)$. Vegetable selection and consumption and white milk selection also increased significantly in the treatment schools $(p<0.001)$, though were not significant overall. Conclusions: The fruit intervention increased the selection and consumption of fruits overall, and increased the selection and consumption of vegetables and the selection of white milk in treatment schools. These findings provide evidence supporting the use of fruit-promoting 
Smarter Lunchrooms techniques in middle schools to increase the selection and consumption of healthy food items. 


\section{INTRODUCTION}

Childhood obesity continues to be a significant public health issue despite worldwide attention and resources made available to combat the problem. Currently, 31.8\% of children aged 2-19

years in the U.S. are considered either overweight or obese. ${ }^{1}$ At the simplest level, overweight and obesity are the result of an imbalance between consumed and expended energy. ${ }^{2-4}$

Contributing to this imbalance are a multitude of factors, including genetic, societal, behavioral, economic, and environmental influences. ${ }^{5}$ All of these together can be referred to as the “obesogenic environment," which has been defined by Swinburn et al. ${ }^{6}$ as "the sum of influences that the surroundings, opportunities, or conditions of life have on promoting obesity in individuals or populations." These influences include the availability, accessibility, and promotion of foods. ${ }^{7}$

For those interested in impacting the food environment, interventions that increase the convenience, attractiveness, and normalness of healthy options have offered effective means to improve food choices. ${ }^{8}$ Applied broadly, this concept can be stated as arranging the environment so that the healthy choices become the easiest choices. By subtly modifying the environment to nudge individuals toward healthier choices, this method of influencing choice avoids the conflicts often associated with restrictive rules or policies. ${ }^{9}$ It has been argued that these strategies could be used to successfully modify health-related behaviors, and encourage healthier eating choices. ${ }^{9,10}$

The school setting is often identified as a key opportunity to address childhood obesity. ${ }^{11,12}$ With more than 30 million children purchasing a U.S. Department of Agriculture-sponsored school 
lunch each day, the school lunchroom is a particularly relevant food environment to address. ${ }^{13}$ In recent years, there have been a number of experiments conducted to explore the possibilities of utilizing strategies of behavioral and environmental change in the school cafeteria. For example, the Smarter Lunchrooms Movement was specifically developed to provide school cafeterias with simple, low- or no-cost solutions based on principles of environmental nudges to encourage students to make healthier food choices. ${ }^{14}$ Promising findings from these studies include: Cutting whole fruit into slices increased fruit selection and consumption ${ }^{15}$; improving presentation of fruit by using attractive and colorful bowls increased selection of fruits ${ }^{16}$; providing vegetables with creative names increased vegetable consumption ${ }^{17}$; and moving fruit to a prominent location on the lunch line increased selection of fruit. ${ }^{14}$

Although the results of these studies are encouraging, they are not readily generalizable owing to limitations including small sample sizes and homogenous or unrepresentative school samples. Additionally, these studies have only measured the impact of single lunchroom changes. With these limitations in mind, the current study builds upon the knowledge and results gained from previous research to examine the effects of multiple fruit-promoting Smarter Lunchroom techniques on a larger scale, and in variety of school types. Given the school-based nature of this study, a cluster design was required. The present research is part of a 5-year, multidisciplinary research project assessing Smarter Lunchrooms techniques, with an overarching goal to improve the food choices made by middle school children. In this work, principles of behavioral economics are used to make small, low- or no-cost environmental changes to school lunchrooms to "nudge" children to select healthier options. These environmental changes incorporate principles of visibility, convenience, taste expectations, and social norms. The authors 
hypothesize that the combination of multiple fruit-promoting Smarter Lunchrooms changes will increase the selection and consumption of fruits in the cafeteria by middle school students. This hypothesis is analyzed at the school level.

\section{METHODS}

\section{Study Sample}

Eleven middle schools (Grades 5-8) from Upstate New York were recruited by local Cornell Cooperative Extension (CCE) staff to participate in the lunchroom study in the spring semester of 2014. One recruited school district declined to participate, resulting in a final sample of ten schools. To ensure inclusion of multiple school types and a demographically diverse sample, schools were recruited from both urban and rural counties as defined by the Office of Management and Budget Metropolitan Statistical Area Designation. ${ }^{18}$ The selection of counties was also influenced by the availability of CCE staff to support the project. Each participating school was required to submit a signed letter of support to consent to participating in the project.

After agreeing to participate, each school was randomly assigned to one of three groups: fruit treatment $(n=4)$, vegetable treatment $(n=3)$, or control $(n=3)$. Power calculations completed for prior similar lunchroom studies determined 1,550 and 1,050 tray observations were necessary to detect a change of $10 \%$ for fruits and vegetables, respectively (test power, 0.95). ${ }^{19}$ Using these calculations, the number of schools recruited was determined using school enrollment data to estimate the number of tray observations based on 4-5 observation days. There was no racial or gender bias in the selection of participants. Randomization of schools was completed by the research team using a random number generator to allocate the schools into groups, with at least 
one rural and one urban school in each group. The scope of this paper is limited to the schools assigned to the fruit treatment and control groups.

The fruit treatment schools were trained on how to make fruit-promoting Smarter Lunchrooms changes to their cafeterias, and the control schools received an unrelated training and were instructed to make no changes to their regular cafeteria setup. The control schools were offered Smarter Lunchrooms training post-intervention. The training was provided to cafeteria staff and food service managers by CCE, and took approximately 30-60 minutes to complete. The fruit treatment group schools were instructed to make all of the following lunchroom changes:

1. Fruit is placed first on the line.

2. At least two varieties of fruit are offered.

3. Fruit is offered in at least two separate locations.

4. Cut fruits are displayed in small, attractive cups.

5. Whole fruits are displayed in a large, attractive fruit bowl at eye level.

6. Fruits are labeled with creative names.

7. Creative fruit names are displayed on monthly and daily menus.

8. "Fruit factoids" are displayed on dry-erase boards at eye level.

The creative names were generated by focus groups of middle school students, and the "fruit factoids" were simple, short facts about fruits. During baseline school visits, it was determined that all schools were almost always offering two varieties of fruit (Protocol 2) prior to the start of the project. All intervention materials were purchased or developed by the research team, and provided to the treatment schools. These intervention components were selected based on previous research demonstrating the positive effects of making healthy food options more 
convenient, attractive, and normal to select. ${ }^{8}$ Each intervention component addressed either the convenience (visibility and location) or attractiveness (descriptive names and attractive bowls) of the fruit options in the lunchroom.

The research team conducted a 2-day training session on the project for CCE nutrition education staff, who subsequently provided the school cafeteria staff with training and technical support for the duration of the project. CCE spent approximately 2 hours each week visiting each school (including travel time), in addition to approximately 3 hours recruiting the schools, and 1 hour training the cafeteria staff.

The project consisted of a 3-week pre-intervention period to collect baseline information, and a 6-week intervention period to implement lunchroom changes. The entire project took place throughout February-April 2014. During the intervention period, CCE made weekly site visits to the treatment schools and reported to the research team any issues raised by the staff, or questions about implementation. These visits served as a time for CCE to check in with the cafeteria staff, drop off materials, and identify any difficulties or concerns. Formal process evaluation, including checks of protocol fidelity, was conducted separately from CCE activities. The results of the process evaluation are fully described elsewhere; in brief, food service staff believed the intervention protocols were feasible, though time and space constraints required adjustment to staff routines. ${ }^{19}$ Many liked the provided materials; however, staff motivation and perceived effectiveness of the treatments varied.

\section{Measures}


Trained field researchers visited each cafeteria pre-intervention (February) and during the intervention (March, April) to record tray waste of students who ordered a school lunch. Students were not told about the purpose of the study, and were told that researchers were there to observe the cafeteria. Tray waste was measured by researchers using the quarter-waste method to visually estimate and record the remaining amount of each individual food item on students' trays. ${ }^{20}$ Using this method (reliability of 90\%), researchers documented whether $0 \%, 25 \%, 50 \%, 75 \%$, or $100 \%$ of each food item was left on the tray. To obtain a baseline measure for comparison, the researchers observed a typical serving of each food item prior to the start of the lunch period. The researcher was then able to compare the tray observations with a typical serving to estimate the percentage remaining. For example, an applesauce cup with two spoonfuls remaining would be marked as $25 \%$, whereas a sandwich with two bites taken would be marked as $75 \%$. Data were collected for all food items observed on student trays, and each item was measured as a unit or serving; for example, a half cup of diced fruit was considered a serving, as was a whole fruit such as an apple. During analysis, fruit juices were considered in the fruit category; however, fruit-based desserts were not. All field researchers were trained on the quarter-waste method prior to visiting the cafeterias, and the data were reviewed for errors during data entry. Only tray observations were identified and were not linked to individual students. As a result, it cannot be known how often the same student was observed, or to compare individual students over time. Though the observational unit was student trays, these data were analyzed at the school level.

Cafeterias were visited an average of 5 days pre-intervention, and an average of 4 days throughout the intervention period. Data were collected during all lunch periods during these days, for a total of 8,502 tray observations (4,475 fruit treatment, 4,027 control). Seven hundred 
fifty of these observations were removed from the data set because of errors, for a final sample of 7,752 (4,139 treatment, 3,613 control). The removed data were clustered around 2 days, and stemmed from incorrect coding used during data collection. These errors impacted both control and treatment schools; however, a large enough sample remained to conduct analysis. The number of visits to each school was determined based on school enrollment and average daily National School Lunch Program participation in order to obtain a similar number of observations at each school. Observation days at each school were strategically chosen to match for menu items to ensure similar food items were being offered during dates of tray waste data collection. Menus were matched based upon the main daily entrees; for example, a chicken patty could be matched with a similar option such as chicken nuggets. Owing to this menu matching, schools were sometimes observed on consecutive days, and other times only observed once per week.

\section{Statistical Analysis}

Using data from tray waste collection, selection was analyzed as the number of items chosen in each food category (fruits, vegetables, milk), and consumption was analyzed as the amount eaten given positive selection of the item. Stata, version 14 was used for data analysis. Researchers initially coded waste data in the lunchroom, and selection and consumption data were then coded later based on the wasted items on the tray. Consumption across all the trays (including trays without positive selection of the item) was also analyzed and reported in Table 2.

Though there was not a specific hypothesis related to vegetables or milk for this study, these categories were included in the analysis because they represent two components of a reimbursable school lunch (fruit, vegetable, milk, meat/meat alternative, grain) and are therefore selected by a large number of students on a daily basis. ${ }^{21}$ The reported values represent the 
average amount of food items selected or consumed for treatment and control schools. As the type of served fruits and vegetables varied by day and by school it is difficult to analyze the items by volume. Therefore, the unit of analysis was chosen to be the serving of a fruit, vegetable, or a milk carton without specifying the exact volume of the served item. Available fruits were served as fresh or canned (e.g., banana, applesauce, diced pears), and vegetables were served either raw or cooked (e.g., salad, sautéed spinach, baked sweet potatoes). The measures were clustered across the ten schools and averaged out by the treatment groups.

The average selection and consumption of food items are reported with SEs in Table 2; though for clarity, the percentage change as well as the average units from pre to post periods are presented within the text. To analyze the statistical difference between treatment and control groups for pre- and post-intervention selection and consumption, $t$-test statistics and differencein-difference analysis were used (Appendix $\mathrm{A}^{22,23}$ ). For a check of robustness, results are presented from both a clustered analysis with and without control variables (Table 2). The clustered analysis assumes that observations are clustered across schools. Additionally, the clustered analysis controlled for differences in race/ethnicity, as well as economic disadvantage. The results of both models were similar; therefore, only the results of clustered analysis with controls have been included in the text.

This study was approved by Cornell University's IRB.

\section{RESULTS}


In total, $4,283(55.25 \%)$ of the final sample of 7,752 trays contained fruits. The pre-intervention distribution of trays that contained any type of fruit was 2,553 of 4,654 (54.86\%), and the postintervention distribution was 1,730 of 3,098 (55.84\%). Average fruit selection (Table 2, Figure 1) in treatment schools increased from 0.59 to 0.80 units of fruit or by $36 \%(p<0.001)$ and decreased in control schools from 0.64 to 0.50 units of fruit or by $22 \%(p<0.001)$. Difference-indifference analysis indicated a $36 \%$ increase in fruit selection as a result of the intervention $(p<0.001)$. Average fruit consumption increased in treatment schools by 0.10 units or by $14 \%$ $(p<0.001)$, and decreased in control schools by 0.14 units or $16 \%(p<0.001)$. Difference-indifference analysis indicated a $23 \%$ increase in fruit consumption as a result of the intervention $(p<0.001)$.

Average vegetable selection increased in treatment schools by $46 \%(p<0.001)$ from 0.67 to 0.98 units, though also increased in control schools from 0.81 to 0.89 , or by $10 \%(p=0.004)$. As a result, the difference-in-difference analysis indicated that the fruit intervention had an overall insignificant positive impact on vegetable selection $(p=0.074)$. Average vegetable consumption increased in treatment schools by $51 \%(p<0.001)$ from 0.57 to 0.86 units, and increased in control schools by $34 \%$ ( $p<0.001)$ from 0.80 to 1.07 . Further difference-in-difference analysis did not indicate a significant impact of the fruit intervention on vegetable consumption $(p>0.10)$.

The average selection of milk increased in treatment schools by $40 \%(p<0.001)$ from 0.10 to 0.14 units, and decreased in control schools by $25 \%(p<0.001)$ from 0.28 to 0.21 units. Difference-indifference analysis indicated that milk selection increased by $10 \%$ as a result of the intervention; however, these results were not significant. The impact of the fruit intervention on average 
consumption of milk in treatment schools was not significant; however, milk consumption decreased in all control schools by $7 \%(p=0.006)$ from 0.84 to 0.78 units. Difference-indifference analysis revealed no significant impact of the intervention on milk consumption.

\section{DISCUSSION}

Previous pilot studies have demonstrated that Smarter Lunchroom techniques can increase selection and decrease waste of targeted food items. ${ }^{15-17}$ Building on these results, the present study demonstrated that implementing specific fruit-promoting strategies increased the selection and consumption of fruits, and partially impacted the selection and consumption of vegetables and milk. Although the fruit-promoting Smarter Lunchrooms interventions were designed and expected to influence fruit outcomes, the fruit-promoting strategies also had a weak but unexpected impact on the selection and consumption of vegetables and milk. The observed increases in consumption are particularly important as this indicates that in addition to more nutrient-rich foods being eaten, fewer of these items are ending up in the garbage. Though the overall impacts on vegetables and white milk were not significant, the possibility of a spillover effect has implications for further research on the subject.

This raises the possibility that interventions may not need to be as directly targeted to a particular category of food items. Instead, it is possible that exposure to the fruit-promoting environmental changes may have stimulated students' awareness of being "healthy," and motivated them to select other food items that fall into the healthy category. It has been argued that sustainability should be taken into account when proposing possible interventions, and along with the low cost of the intervention components, a spillover effect may help address this issue. ${ }^{24}$ For example, 
schools can make simple lunchroom changes without having to target each specific food item or category. Secondly, different Smarter Lunchroom changes could be rotated throughout the year, to provide novel stimuli to students who may become desensitized to the changes.

\section{Limitations}

Although 750 observations were removed from the data set because of errors, there remained sufficient numbers of observations remaining to determine statistical significance. As schools were visited during the days when they had similar menu items, the removal did not impact the overall quality of the data or bias it toward any specific food items. Even with an average of only 9 days of tray observations per school, the effects of the intervention were significant. These findings provide encouragement that a longer-term investigation of these lunchroom changes could result in a greater increase in selection and consumption of healthy items. Additional days of tray observations could estimate more precisely the effects of these simple and low-cost environmental interventions.

Tracking individual students in this study was not feasible owing to practical and IRB limitations. As a result, the tray observations from each school are assumed to be obtained from generally the same sample of students. This limitation was the rationale for the unit of measurement being trays, and not students, as that would artificially inflate the sample size. Future research could attempt to address the barriers to tracking individual students. Lastly, though this field trial was conducted in a relatively wide and diverse set of schools, given the high percentage of economic disadvantage in all participating schools ( $\geq 49 \%$ ), the results may not be generalizable to all schools. 
The prevalence of obesity in the U.S. continues to be a public health concern, and great focus has been put on preventing overweight and obesity from developing in childhood. High rates of obesity are even more alarming when considering the medical complications and chronic diseases that have been documented in not only adults, but in children as well. ${ }^{25}$

As environmental and behavioral factors are thought to contribute to the development of overweight and obesity, significant research has been concentrated on finding ways to change eating behavior of both adults and children. Schools are particularly attractive for researchers, as it is the environment where students spend the most time outside of their homes. ${ }^{26}$ Previous small-scale studies of Smarter Lunchrooms techniques have measured the impact of a single change (i.e., nudge) on the selection and waste of targeted items. This study built on the knowledge generated from previous findings in school cafeterias, and conducted a combination of these interventions on a larger scale.

\section{CONCLUSIONS}

The results of this study provide evidence that multiple fruit-promoting lunchroom changes are a successful and feasible method to increase selection and consumption of fruits. The fruit interventions also had an unexpected positive impact on the selection and consumption of vegetables and the selection of milk in the treatment group. However, the positive results observed for vegetables and milk in the treatment group were not significant when compared with the control group. The findings of this study bolster previous positive results of Smarter Lunchrooms research, and have greater generalizability given the diversity of the school sample. These positive findings open up the door for additional research into other types of Smarter 
Lunchrooms environmental changes, including the implementation of changes targeting multiple food categories simultaneously. 


\section{ACKNOWLEDGMENTS}

This project was supported by Agriculture and Food Research Initiative Grant no. 2012-6800119604 from the U.S. Department of Agriculture National Institute of Food and Agriculture, Childhood Obesity Prevention: Integrated Research, Education, and Extension to Prevent Childhood Obesity-A2101. Any opinions, conclusion, findings, or recommendations expressed in this publication are those of the authors and do not necessarily reflect the view of the U.S. Department of Agriculture. The authors would like to acknowledge the contributions of Jamie Dollahite, PhD, Tisa Hill, MPH, Laura Thomas, PhD, Lara Latimer, PhD, Adam Brumberg, and Cornell Cooperative Extension. Lastly, the authors would like to thank all of the school districts and school food service staff for their participation in this study.

Ms. Greene interpreted the data, drafted and revised the initial manuscript, and approved the final manuscript as submitted. Dr. Gabrielyan carried out the initial analyses and interpretation, reviewed and revised the manuscript, and approved the final manuscript as submitted. Drs. Just and Wansink designed the study and data collection instruments, supervised data collection, critically reviewed the manuscript, and approved the final manuscript as submitted. All authors agree to be accountable for all aspects of the work in ensuring that questions related to the accuracy or integrity of any part of the work are appropriately investigated and resolved.

No financial disclosures were reported by the authors of this paper. 


\section{REFERENCES}

1. Ogden CL, Carroll MD, Kit BK, Flegal KM. Prevalence of childhood and adult obesity in the United States, 2011-2012. JAMA. 2014;311(8):806-814. https:/doi.org/10.1001/jama.2014.732.

2. Wright SM, Aronne LJ. Causes of obesity. Abdom Imaging. 2012;37(5):730-732. https:/doi.org/10.1007/s00261-012-9862-x.

3. Pratt CA, Stevens J, Daniels S. Childhood obesity prevention and treatment: Recommendations for future research. Am J Prev Med. 2008;35(3):249-252. https:/doi.org/10.1016/j.amepre.2008.05.025.

4. Wofford LG. Systematic review of childhood obesity prevention. J Pediatr Nurs. 2008;23(1):5-19. https:/doi.org/10.1016/j.pedn.2007.07.006.

5. Aronne LJ, Nelinson DS, Lillo JL. Obesity as a disease state: A new paradigm for diagnosis and treatment. Clin Cornerstone. 2009;9(4):9-29. https:/doi.org/10.1016/S1098-3597(09)80002-1.

6. Swinburn B, Egger G, Raza F. Dissecting obesogenic environments: The development and application of a framework for identifying and prioritizing environmental interventions for obesity. Prev Med. 1999;29(6):563-570. https:/doi.org/10.1006/pmed.1999.0585.

7. Lake A, Townshend T. Obesogenic environments: Exploring the built and food environments. J R Soc Promot Health. 2006;126(6):262-267. https:/doi.org/10.1177/1466424006070487. 
8. Wansink B. Change their choice! changing behavior using the CAN approach and activism research. Psychology \& Marketing. 2015;32(5):486-500. https:/doi.org/10.1002/mar.20794.

9. Hanks AS, Just DR, Wansink B. Smarter lunchrooms can address new school lunchroom guidelines and childhood obesity. J Pediatr. 2013;162(4):867-869. https:/doi.org/10.1016/j.jpeds.2012.12.031.

10. Loewenstein G, Brennan T, Volpp KG. Asymmetric paternalism to improve health behaviors. JAMA. 2007;298(20):2415-2417. https:/doi.org/10.1001/jama.298.20.2415.

11. U.S. DHHS, Public Health Service, Office of the Surgeon General. The Surgeon General's Call to Action to Prevent and Decrease Overweight and Obesity. www.cdc.gov/nccdphp/dnpa/pdf/calltoaction.pdf. Published 2001. Accessed August 25, 2016.

12. Koplan JP, Liverman CT, Kraak VA, Editors. Preventing childhood obesity: Health in the balance. Washington, DC: National Academies Press; 2005.

13. U.S. Department of Agriculture, Food and Nutrition Service. National school lunch program: Participation and lunches served. www.fns.usda.gov/sites/default/files/pd/slsummar.pdf. Updated August 5, 2016. Accessed August 25, 2016.

14. Just DR, Wansink B. Smarter lunchrooms: Using behavioral economics to improve meal selection. Choices. 2009;24(3):1-7.

15. Wansink B, Just DR, Hanks AS, Smith LE. Pre-sliced fruit in school cafeterias: Children's selection and intake. Am J Prev Med. 2013;44(5):477-480. https:/doi.org/10.1016/j.amepre.2013.02.003. 
16. Wansink B, Just D, Smith L. Move the fruit: Putting fruit in new bowls and new places doubles lunchroom sales. J Nutr Educ Behav. 2011;43(4):S1. https:/doi.org/10.1016/j.jneb.2011.03.013.

17. Wansink B, Just DR, Payne CR, Klinger MZ. Attractive names sustain increased vegetable intake in schools. Prev Med. 2012;55(4):330-332. https:/doi.org/10.1016/j.ypmed.2012.07.012.

18. Office of Management and Budget. Revised delineations of metropolitan statistical areas, micropolitan statistical areas, and combined statistical areas, and guidance on uses ofthe delineations of these areas. OMB BULLETIN NO. 13-01. www.whitehouse.gov/sites/default/files/omb/bulletins/2013/b-13-01.pdf. Published February 22, 2013. Accessed August 25, 2016.

19. Thomas LN, Hill TF, Gaines A, Dollahite JS. Implementing Smarter Lunchroom Makeovers in New York State middle schools: An initial process evaluation. Arch Public Health. 2016;74:41. https:/doi.org/10.1186/s13690-016-0153-9.

20. Hanks AS, Wansink B, Just DR. Reliability and accuracy of real-time visualization techniques for measuring school cafeteria tray waste: Validating the quarter-waste method. J Acad Nutr Diet. 2014;114(3):470-474. https:/doi.org/10.1016/j.jand.2013.08.013.

21. U.S. Department of Agriculture, Food and Nutrition Service. USDA's New Meal Pattern in Schools. www.fns.usda.gov/sites/default/files/Mealpatternppt.pdf. Published July 2013. Accessed August 25, 2016.

22. Everitt B, Landau S, Leese M, Stahl D. Cluster Analysis. Chichester, West Sussex, U.K.: Wiley; 2011. https:/doi.org/10.1002/9780470977811. 
23. Gordon A. Classification. 2nd ed. Boca Raton, FL: Chapman \& Hall/CRC; 1999.

24. Jackson N, Waters E, Guidelines for Systematic Reviews in Health Promotion and Public Health Taskforce. Criteria for the systematic review of health promotion and public health interventions. Health Promot Int. 2005;20(4):367-374. https:/doi.org/10.1093/heapro/dai022.

25. Daniels S. Complications of obesity in children and adolescents. Int J Obes. 2009;33:S60-S65. https:/doi.org/10.1038/ijo.2009.20.

26. Story M, Nanney MS, Schwartz MB. Schools and obesity prevention: Creating school environments and policies to promote healthy eating and physical activity. Milbank $Q$. 2009;87(1):71-100. https:/doi.org/10.1111/j.1468-0009.2009.00548.x. 


\section{LIST OF FIGURES}

Figure 1. Impact of fruit-focused Smarter Lunchrooms interventions on the average selection and consumption of fruits, vegetables, and white milk.

Note: Averages represent sample means of observed items across all trays (e.g., a mean fruit selection of 0.64 indicates that 0.64 units of fruit were selected on an average tray).

Figure 2. CONSORT flow diagram. 
Table 1. Demographic Characteristics of School Sample for Fruit Intervention by Treatment Group

\begin{tabular}{rllrrrrrr}
\hline & Group & Location & $\begin{array}{c}\text { Enrollment } \\
\text { (Grades 5-8) }\end{array}$ & \% White & \% Black & \% Hispanic & Other & $\begin{array}{c}\text { \% Economic } \\
\text { Disadvantage }^{\text {a }}\end{array}$ \\
\cline { 2 - 9 } 1 & Treatment & Urban & 201 & $1 \%$ & $91 \%$ & $5 \%$ & $2 \%$ & $85 \%$ \\
2 & Treatment & Urban & 312 & $6 \%$ & $19 \%$ & $72 \%$ & $3 \%$ & $92 \%$ \\
3 & Treatment & Rural & 327 & $92 \%$ & $1 \%$ & $4 \%$ & $3 \%$ & $57 \%$ \\
4 & Treatment & Rural & 418 & $97 \%$ & $2 \%$ & $1 \%$ & $1 \%$ & $55 \%$ \\
5 & Control & Urban & 202 & $13 \%$ & $34 \%$ & $6 \%$ & $47 \%$ & $92 \%$ \\
6 & Control & Urban & 261 & $5 \%$ & $84 \%$ & $5 \%$ & $7 \%$ & $86 \%$ \\
7 & Control & Rural & 387 & $90 \%$ & $4 \%$ & $4 \%$ & $2 \%$ & $49 \%$ \\
\hline
\end{tabular}

Source: New York State Education Department, 2013-14 Enrollment

${ }^{a}$ Economic Disadvantage is defined as: students who participate in, or whose family participates in economic assistance programs, such as the free or reduced-price lunch program. 
Table 2. Means ${ }^{\mathrm{a}}$ and T-test Results for Selection and Consumption ${ }^{\mathrm{b}}$ of Fruits, Vegetables, and White Milk Pre- and Post-intervention

\begin{tabular}{|c|c|c|c|c|c|}
\hline \multirow[t]{2}{*}{ Measure } & \multirow{2}{*}{$\begin{array}{c}\text { Pre } \\
\text { Mean (SE) }\end{array}$} & \multirow{2}{*}{$\begin{array}{c}\text { Post } \\
\text { Mean (SE) } \\
\end{array}$} & \multirow{2}{*}{$\begin{array}{c}\begin{array}{c}\text { T-test } \\
(p \text {-value })\end{array} \\
\text { Pre } \neq \text { Post }\end{array}$} & \multicolumn{2}{|c|}{$\begin{array}{c}\text { Diff-in-diff coefficient } \\
\text { Clustered regressions } \\
(p \text {-value })\end{array}$} \\
\hline & & & & Without control variables & With control variables \\
\hline \multicolumn{6}{|l|}{ Fruit selection } \\
\hline Control & $0.64(0.64)$ & $0.50(0.60)$ & $<0.001$ & - & - \\
\hline Treatment & $0.59(0.59)$ & $0.80(0.61)$ & $<0.001$ & $0.344(<\mathbf{0 . 0 0 1})$ & $0.366(<\mathbf{0 . 0 0 1})$ \\
\hline \multicolumn{6}{|l|}{ Fruit consumption } \\
\hline Control & $0.85(0.55)$ & $0.71(0.56)$ & $<0.001$ & - & - \\
\hline Treatment & $0.73(0.50)$ & $0.83(0.48)$ & $<0.001$ & $0.242(\mathbf{0 . 0 2 6})$ & $0.227(\mathbf{0 . 0 1 7})$ \\
\hline Control & $0.47(0.59)$ & $0.32(0.51)$ & $<0.001$ & & \\
\hline Treatment & $0.40(0.52)$ & $0.58(0.55)$ & $<0.001$ & $0.335(\mathbf{0 . 0 0 1})$ & $0.339(\mathbf{0 . 0 0 1})$ \\
\hline \multicolumn{6}{|l|}{ Vegetable selection } \\
\hline Control & $0.81(0.76)$ & $0.89(0.89)$ & 0.004 & - & - \\
\hline Treatment & $0.67(0.74)$ & $0.98(0.83)$ & $<0.001$ & $0.233(0.107)$ & $0.246(0.074)$ \\
\hline \multicolumn{6}{|c|}{ Vegetable consumption } \\
\hline Control & $0.80(0.51)$ & $1.07(0.69)$ & $<0.001$ & - & - \\
\hline Treatment & $0.57(0.52)$ & $0.86(0.58)$ & $<0.001$ & $0.022(0.868)$ & $0.062(0.701)$ \\
\hline Control & $0.48(0.56)$ & $0.61(0.74)$ & $<0.001$ & & \\
\hline Treatment & $0.29(0.47)$ & $0.57(0.63)$ & $<0.001$ & $0.153(0.196)$ & $0.191(0.180)$ \\
\hline \multicolumn{6}{|c|}{ White milk selection } \\
\hline Control & $0.28(0.46)$ & $0.21(0.42)$ & $<0.000$ & - & - \\
\hline Treatment & $0.10(0.30)$ & $0.14(0.35)$ & $<0.001$ & $0.107(0.082)$ & $0.101(0.076)$ \\
\hline \multicolumn{6}{|c|}{ White milk consumption } \\
\hline Control & $0.84(0.34)$ & $0.78(0.37)$ & 0.006 & - & - \\
\hline Treatment & $0.76(0.39)$ & $0.76(0.36)$ & 0.875 & $0.061(0.344)$ & $0.091(0.259)$ \\
\hline Control & $0.23(0.41)$ & $0.17(0.36)$ & $<0.001$ & & \\
\hline Treatment & $0.07(0.25)$ & $0.11(0.30)$ & $<0.001$ & $0.095(0.091)$ & $0.098(\mathbf{0 . 0 7 2})$ \\
\hline
\end{tabular}

Note: Boldface indicates statistical significance $(p<0.05)$.

${ }^{\mathrm{a}}$ Mean values represent sample means of observed respective items across all trays (e.g., a mean fruit selection of 0.64 indicates that

0.64 units of fruit were selected on an average tray).

${ }^{\mathrm{b}}$ Consumption conditional to selection as well as overall consumption across all trays (Italics) are reported. 


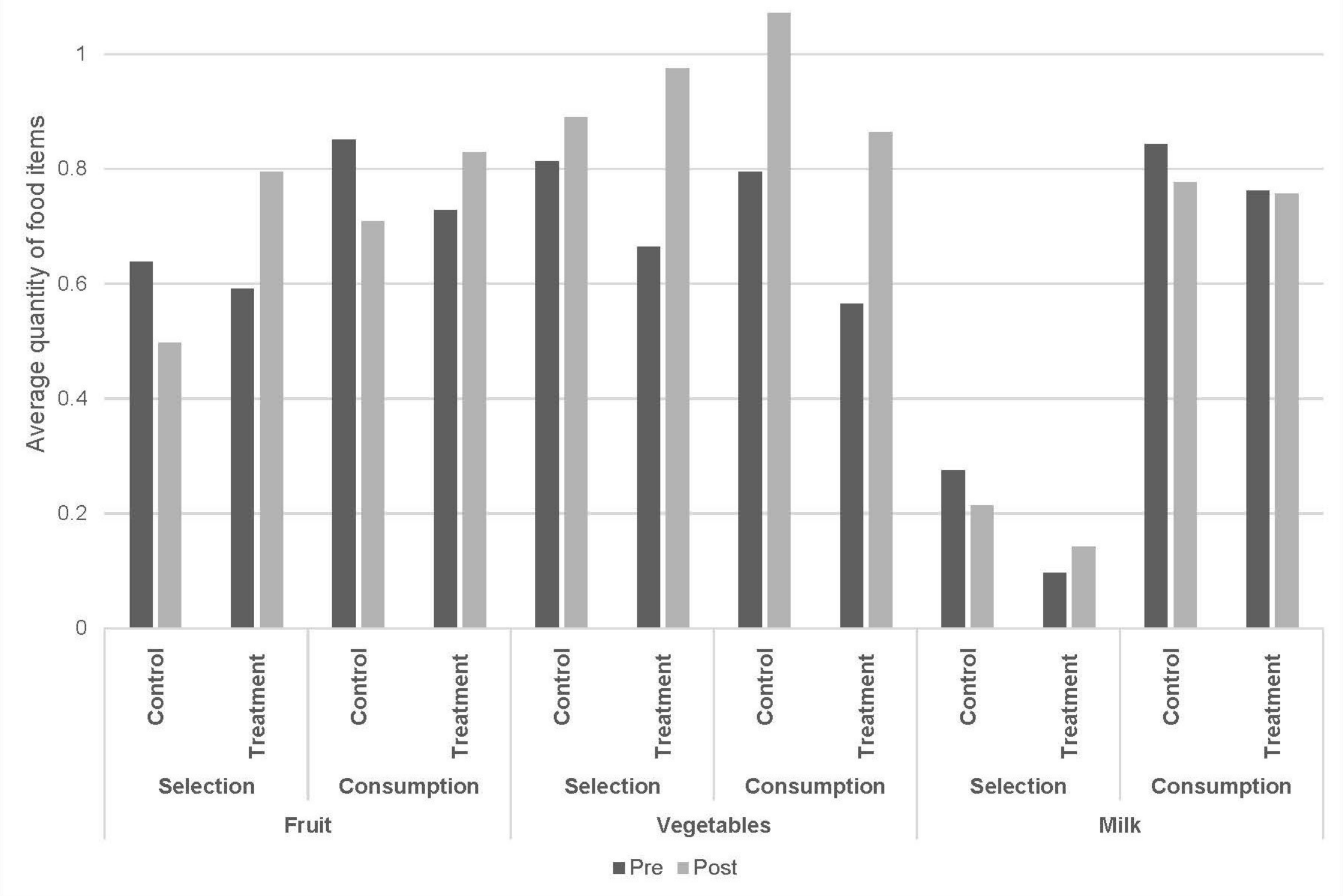




\section{Enrollment}

Assessed for eligibility $(n=11)$

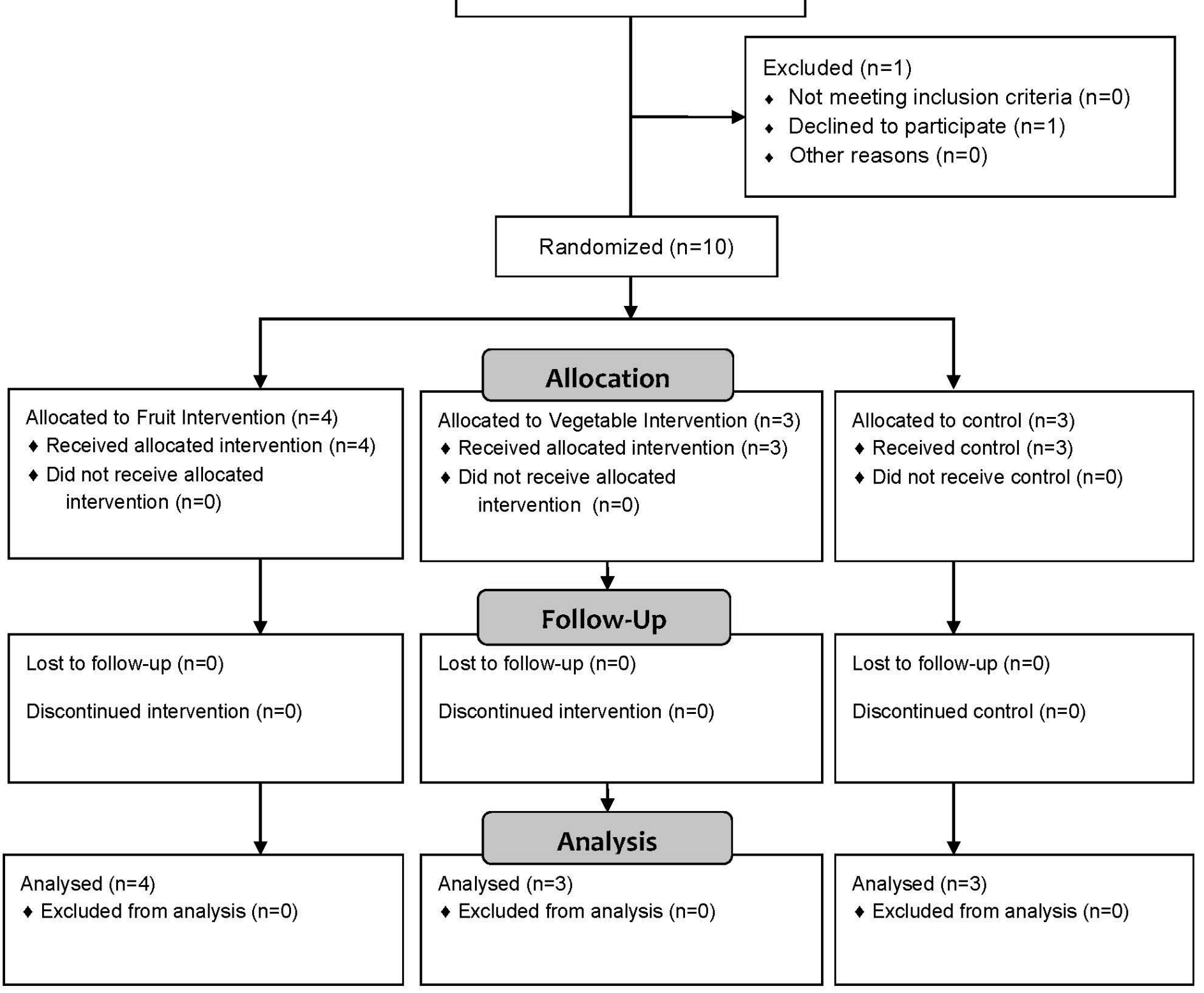

